\title{
Knowing the Role of Supplementary Nutrition and Growth Monitoring from the Beneficiaries of Selected Anganwadi Centers in Rural Wardha, Maharashtra
}

\section{Samarpita Dutta ${ }^{1 *}$ and Abhishek V Raut ${ }^{2}$}

${ }^{1}$ Tripura Health Service, Agartala Government Medical College, Agartala, India

${ }^{2}$ Community Medicine, Mahatma Gandhi Institute of Medical Sciences, Wardha, India

*Corresponding Author: Samarpita Dutta, Tripura Health Service, Agartala

Government Medical College, Agartala, India.
Received: August 24, 2020

Published: October 07, 2020

(C) All rights are reserved by Samarpita Dutta and Abhishek V Raut.

\section{Abstract}

Launched in 1975 by the Government of India, the ICDS scheme is currently the most important scheme in the field of child health and development and care of women throughout their critical stages in life. With four decades of implementation of this scheme, it is imperative to take stock of this flagship programme from its basic level of implementation in the country. The present study was thus conducted to determine the facilities available at selected Anganwadi centers and find out the concerns and performance of the Anganwadi Workers through observation, review of records and interviews.

The study was conducted in 2 phases over a period of 3 months, in 15 Anganwadi Centers of the field practice area of a Rural Health Training Centre in Wardha district, Maharashtra. The $1^{\text {st }}$ phase consisted of facility survey using pre-designed checklist while the $2^{\text {nd }}$ phase consisted of in-depth interviews with the respective Anganwadi Workers.

Facility survey revealed lack of storage, kitchen and toilet facilities in 5, 2 and 6 centers respectively. Hot Cooked Food was being served at 11 of the 15 centers. Peoples' concern regarding quality of take home recipes, immunization days and improper utilization of learning material emerged as important issues compromising health promotion and pre-school education activities during the in-depth interviews.

Bottlenecks identified through key functionaries of the scheme at community level would enable the administration take up coordinated steps to make it locally acceptable and reliable towards a fruitful impact in the nation.

Keywords: Anganwadi Centers; Supplementary Nutrition; Integrated Child Development Services; In-Depth Interviews

\section{Abbreviations}

ICDS: Integrated Child Development Services; HCF: Hot Cooked Food; THR: Take Home Recipe; RTE: Ready to Eat; AWC: Anganwadi Center; SN: Supplementary Nutrition; AWW: Anganwadi Worker

\section{Introduction}

Health of pre-school children is of paramount importance because the foundation for lifetime strength and intellectual vitality is laid during this time. It is the period when maximum physical and mental growth occurs and also it is the most vulnerable period for the development of malnutrition and infectious diseases. The Integrated Child Development Services (ICDS) scheme is cur- rently the most important scheme in the field of child welfare. The scheme was initiated and launched by the Government of India under the Ministry of Social and Women's Welfare on $2^{\text {nd }}$ of October in the year 1975 in pursuance of the National Policy for Children [1]. It provides an integrated approach for converging all the basic services for improved child care, early stimulation and learning, health and nutrition, water and environmental sanitation aimed at young children, pregnant and lactating mothers, other women and adolescent girls in the community [2]. ICDS being an integrated package of early childhood services includes supplementary nutrition, immunization, health checkup, medical referral services, nutrition and health education for women, pregnant and lactating mothers 
Knowing the Role of Supplementary Nutrition and Growth Monitoring from the Beneficiaries of Selected Anganwadi Centers in Rural Wardha, Maharashtra

as well as non- formal education of children up to 6 years of age [3].

In India, a total of 7076 projects are being run under the ICDS with 12.42 lakh Anganwadi centers and 1,13,151 Mini -Anganwadi centers [1]. In the state of Maharashtra presently there are 553 projects covering a population $86,31,910$ children of 0 - 6 yrs age from among the total 0 - 6 yrs population of 1,37,87,087 in the state as per Census, 2001 [4].

With years of this service being run through the projects and regular expansion of the projects, a number of evaluation studies on implementation of the ICDS scheme have been conducted in the past viz., National evaluation of ICDS scheme conducted by National Institute of Public Co-operation and Child Development (NIPCCD) in 1992, Nationwide Evaluation of ICDS scheme by National Council of Applied Economic Research (NCAER) in 1988-89 [2]. Even after 30 years of implementation of ICDS, about $39.7 \%$ below 3 years children in Maharashtra were found undernourished and only 50\% used Anganwadi services in the last 12 months (NFHS 2008) [5].

The poor utilization of a flagship program of the Government of the country, with robust potential for optimizing women and child health and development thus demands speculation and understanding of the problems at ground level. A study was therefore conducted in selected Anganwadi centers of Wardha with a view to study the provisions and performance of Anganwadi Workers through review of records, observation and interview.

\section{Materials and Methods}

The study was conducted in 2 phases over a period of 3 months, in 15 Anganwadi Centers of the field practice area of a Rural Health Training Centre in Wardha district, Maharashtra. The 1st phase consisted of facility survey using pre-designed checklist while the $2^{\text {nd }}$ phase consisted of in-depth interviews with the respective Anganwadi Workers. After selection of the villages, one Anganwadi Centre from each village was selected, randomly for those villages having more than one AWC. The study was conducted by visiting each of these villages in two phases using a pre-scheduled work plan. During the first visit, a pre-designed checklist was used for facility survey followed by observation of records. A date and time was also fixed with the Anganwadi Worker for the in-depth interview scheduled in the $2^{\text {nd }}$ phase after obtaining an informed consent from them. However, for the in-depth interview, the participants did not consent for audio recording and hence no audio recording was done.

\section{Results}

Anganwadi workers' profile

Anganwadi Worker (AWW) is the key person in delivering the ICDS services in the villages. In the present study, interview revealed that, while 8 of the 15 AWWs had completed their education upto $9^{\text {th }}$ or $10^{\text {th }}$ standard (53\%), 6 of them had also studied beyond tenth standard and completed either $11^{\text {th }}$ or $12^{\text {th }}$ standard $(40 \%)$ and only one of them educated upto $8^{\text {th }}$ standard. None of the AWWs had graduated. Most of them (93.3\%) were in this service for more than 10 years, except for one who was in service since the last 9 years.

The training provided to the AWW consists of a 7 day induction training course and a detailed 30 day job training course with periodical refresher training courses. All the AWWs interviewed in the present study had undergone training following recruitment into their jobs. While 8 of them had received 2 trainings, 5 of them received 3 trainings only 1 each received only 1 or 4 trainings respectively. Workers however could not recall the dates or classify them as induction, job or refresher training (Table 1).

\begin{tabular}{|c|c|c|c|}
\hline Sr. No. & Characteristics & $\begin{array}{c}\text { Number of } \\
\text { subjects } \\
\text { (AWW) }\end{array}$ & $\begin{array}{c}\text { Percentage } \\
(\%)\end{array}$ \\
\hline \multirow[t]{5}{*}{1.} & Educational qualification & & \\
\hline & $6^{\text {th }}-8^{\text {th }} s t d$ & 1 & 6.7 \\
\hline & $9^{\text {th }}-10^{\text {th }}$ std & 8 & 53.3 \\
\hline & $11-12^{\text {th }}$ std & 6 & 40.0 \\
\hline & Graduate and above & -- & -- \\
\hline \multirow[t]{5}{*}{2.} & Duration of service & & \\
\hline & $<5$ years & -- & -- \\
\hline & 5 - 10 years & 1 & 6.7 \\
\hline & 10 - 15 years & 14 & 93.3 \\
\hline & > 15 years & -- & -- \\
\hline \multirow[t]{3}{*}{3.} & Job training received & & \\
\hline & Yes & 15 & 100 \\
\hline & No & -- & -- \\
\hline \multirow[t]{5}{*}{4.} & No. of trainings received & & \\
\hline & 1 & 1 & 6.7 \\
\hline & 2 & 8 & 53.3 \\
\hline & 3 & 5 & 33.3 \\
\hline & 4 & 1 & 6.7 \\
\hline
\end{tabular}

Table 1: Anganwadi worker profile. 
Knowing the Role of Supplementary Nutrition and Growth Monitoring from the Beneficiaries of Selected Anganwadi Centers in Rural Wardha, Maharashtra

Infrastructure and other facilities at the Anganwadi centers

Of the 15 Anganwadi centers, 14 of them operated in their own buildings and also $80 \%$ of them from new pucca buildings. There was an apparent shortage of indoor space in 3 of the 15 AWCs (20\%), while apparently 4 such centers had an inadequate outdoor space. Also, a separate kitchen and storage facility was lacking in 2 and 5 of the AWCs respectively. Toilet facility was lacking at 6 (40\%) of the 15 centers, and also in those where toilets existed their use was minimal and maintenance even poorer. There was no facility for storage of water, for use other than drinking. Drinking water although was available in all of the AWCs, their source remained from the tap water supplied from the Gram Panchayat in 12 centers and the remaining stored drinking water from the hand-pumps nearby the centers. After obtaining water from the source no further purification of water was done regularly, except for a few who used chlorine drops irregularly (Table 2).

\begin{tabular}{|c|c|c|c|}
\hline Sr. No. & Facility & $\begin{array}{c}\text { Present } \\
\text { (\%) }\end{array}$ & $\begin{array}{c}\text { Absent } \\
\text { (\%) }\end{array}$ \\
\hline 1. & New building & $12(80)$ & $3(20)$ \\
\hline 2. & Own building & $14(93.3)$ & $1(6.7)$ \\
\hline 3. & Adequate indoor space & $12(80)$ & $3(20)$ \\
\hline 4. & Adequate outdoor space & $11(73.3)$ & $4(26.7)$ \\
\hline 5. & Separate Kitchen & $13(86.6)$ & $2(13.4)$ \\
\hline 6. & Separate store & $10(66.6)$ & $5(33.4)$ \\
\hline 7. & Toilet facility & $9(60.0)$ & $6(40.0)$ \\
\hline 8. & Drinking water availability & $15(100)$ & 0 \\
\hline
\end{tabular}

Table 2: Infrastructure and facilities at the Anganwadi centers.

Services provided at the Anganwadi centers

\section{Supplementary nutrition}

Under the present system operational under ICDS, supplementary nutrition is provided to the beneficiaries in two forms. Food is either prepared at the center itself or distributed through a central distribution system on a daily basis. This is referred to as "Hot Cooked Food" (HCF). Pre prepared food is also provided to the beneficiaries. This food is provided to the centers on a monthly basis and subsequently distributed to the beneficiaries, referred to as the "Ready to Eat Food (RTE)" or "Take Home Recipes" (THR). In the present study, while 11 of the centers provided to their beneficiaries, both THR and HCF, at 4 of the centers there was no provision of HCF. Also 13 of the centers reported a regular supply of the THR from the food distribution system, except for two, where the supply was irregular (Table 3). Food was provided according to a fixed weekly menu at the centers and standard measures for distributing supplementary nutrition were available at the centers.

Most of the AWWs reported smooth functioning of the supplementary nutrition services. A few centers where HCF was not available, lack of support from the community based organizations of the village, which generally undertake the activity of cooking and providing HCF to the children under a contractual system, emerged as an important cause for the interruption in this service. Regarding THR it also emerged that there was poor response from the beneficiaries as most of them complained of poor taste and some of them even doubted its quality.

Anganwadi worker 4. "Very often the mothers complain that their children don't like the taste and so they they do not cook it often".

Anganwadi worker 9. "Some of them also question to us regarding the quality of THR.. They feel that the quality may be definitely compromised as it is provided free of cost. Infact a few of them who collected the packets from the AWC rather used them as fodder for the cattle".

\section{Growth monitoring}

In the present study, Salter's scale was available at all the centers, while growth chart was available in all but 1 of the 15 centers. The centre in which the chart was not available, it later emerged from the interview, that, there was a common growth chart book shared by two AWCs of the same village. Children were weighed on a monthly basis as per the guidelines. However, it was also found in the study that out of 15 AWWs, 12 of them could correctly plot the weight of a randomly selected child on the growth chart on the day of survey, while remaining 3 could not (Table 3 ).

It was routine in the AWCs to perform the growth monitoring activities on the 'Village Health and Nutrition Day' (VHND). Few of them felt that they were too busy on that day noting down the weight and height of the children and often could not communicate well the status of the children to their parents. However they do talk to the parents at other times.

\section{Immunization}

The immunization session was held in all the centers within a period of last one month. It was organized in most of the centers 
Knowing the Role of Supplementary Nutrition and Growth Monitoring from the Beneficiaries of Selected Anganwadi Centers in Rural Wardha, Maharashtra

in collaboration with the Auxiliary Nurse Midwife (ANM) and the Accreditated Social Health Activist (ASHA) of the village. An average attendance of $90 \%$ was recorded at most centers, with only 1 centre having an attendance below $80 \%$.

It emerged from the interviews that routine immunization sessions were well conducted on a prefixed day of the month (VHND), like first Wednesday of every month, second Friday of every month, etc., different days for every village. And both the ASHA and the ANM were present for the session. However problem arose if at any time the session could not be conducted on the stipulated day.

Anganwadi worker 1. "Sometimes all beneficiaries were not present in the village or sometimes few children were taken to some private clinics or at some nearby hospital at Wardha or where they receive the immunization".

Anganwadi worker 9. "It is common in the villages that antenatal women would go to their parents home for delivery of their baby and often would return home only after 2 - 3 months. Hence these newborns or young infants are not available during the immunization sessions. However we ensure that these children have received their required vaccines at their places of visit".

\section{Health check up and referral}

While in only 10 out of the 15 AWCs, a health check up session was held within the last 3 months, which is the recommended norms, in the remaining 5 AWCs it was held before 3 months but within the last 6 months. It was attended by the respective medical officer of the PHC, in 13 centers and by the ANM in 1 centre and by a supervisor in 1 centre. In most of the centers records of last medical checkup session was not available or complete. There was a shortage of medicine kits across the centers with only Paracetamol or Iron Folic Acid tablets available. The centers received medicine kits on an irregular basis and even lesser used them. Referral slips were present at only $9(60 \%)$ centers, but being used by none of them for referral.

\section{Pre school education}

The average attendance of the 3 - 6 years old children registered at the AWCs for pre-school education activities was only 76.1 $\%$ on the day of survey. There was shortage of Pre-School Education (PSE) kits at 8 centers. This compromised the PSE activities at the centers with all child beneficiaries not participating in PSE activities. On an average only $60 \%$ of child beneficiaries of the villages were registered at the AWCs for PSE activities.

The common mode of conducting preschool activities would be in form of prayers, teaching the children to introduce themselves, few rhymes, stories and naming common objects, animals, birds, fruits, vegetables, etc. Only a few of them would do role plays with the help of Anganwadi helper occasionally. Some AWWs told that there was a gradual decline in the number of children registered at the anganwadi centers.

Anganwadi worker 8. "Few well to do families in the village would send their children to some private kindergartens or playschools in and around the villages instead of sending them to the AWCs and this is now becoming a trend".

Regarding use of play objects and games,etc. provided to them for the children they told that often the children would spoil them soon and hence they kept them inside the cupboards in the store and would take them out only occassionally.

\section{Services to adolescents and health education}

Health education sessions were being conducted at 13 of the 15 centers regularly, although there was lack of proper organization of the same. In most centers a single combined session was conducted monthly for mothers of under-5 children, pregnant and lactating women. Adolescent girls were rarely called for health education sessions. From record of the proceeding of the previous meetings, wherever it was available, it was also evident that the topics discussed were not well planned and being repeated in most sessions.

Most of the AWWs felt overworked and said that health education activities were not regular. Often pregnant women, lactating mothers or mothers of underfive showed lack of interest and would not come for the meetings due to their household chores inspite of calling them several times for the meetings. This discouraged them from going over and again to call the beneficiaries for this activity. The same was true for the adolescent girls as they too would be busy with schools and other activities.

Anganwadi worker 3. "Most of the adolescent girls are busy with work at home in the morning hours and in the afternoons they would go to schools...." "Also because it was instructed to us that at a time HCF would be given to only three adolescent girs for a specified duration and then to another three and so on, most of them did not turn up or just came irregularly".

Some AWWs also expressed decreasing interest in rennovation of the centers and expenditure for the benefit of their beneficiaries inspite of funds being sanctioned to them every year, as according to them, the money was held with the members of the Gram Panchayat, who showed less interest and also because the process takes long time. 


\begin{tabular}{|c|c|c|c|}
\hline Sr. No & & Services provided & Frequency (\%) \\
\hline 1. & $\begin{array}{c}\text { Supplementary } \\
\text { nutrition }\end{array}$ & $\begin{array}{ll}\text { - } & \text { Receiving only THR } \\
\text { - } & \text { Receiving THR+HCF } \\
\text { - } & \text { Food supply } \\
\bullet \quad \text { i. regular } \\
\text { - ii. irregular }\end{array}$ & $\begin{array}{l}4(26.6) \\
11(73.4) \\
13(86.7) \\
2(13.3)\end{array}$ \\
\hline 2. & Growth monitoring & $\begin{array}{c}\text { - } \text { Growth chart available } \\
\bullet \quad \text { Yes } \\
\bullet \quad \text { No } \\
\text { - Weighing scales available } \\
\bullet \quad \text { Yes } \\
\bullet \quad \text { No } \\
\text { - } \quad \text { Plot weight correctly }\end{array}$ & $\begin{array}{l}14(93.3) \\
1(6.7) \\
15(100) \\
0 \\
12(80.0)\end{array}$ \\
\hline 3. & $\begin{array}{l}\text { Pre-school educa- } \\
\text { tion activities }\end{array}$ & $\begin{array}{l}\text { - } \text { Average attendance }(\text { mean } \pm \text { SD) } \\
\text { - } \quad \text { PSE kits available } \\
\text { - Yes } \\
\text { - No }\end{array}$ & $\begin{array}{l}76.13( \pm 15.74) \\
7(46.7) \\
8(53.3)\end{array}$ \\
\hline 4. & $\begin{array}{l}\text { Immunization and } \\
\text { health checkups }\end{array}$ & 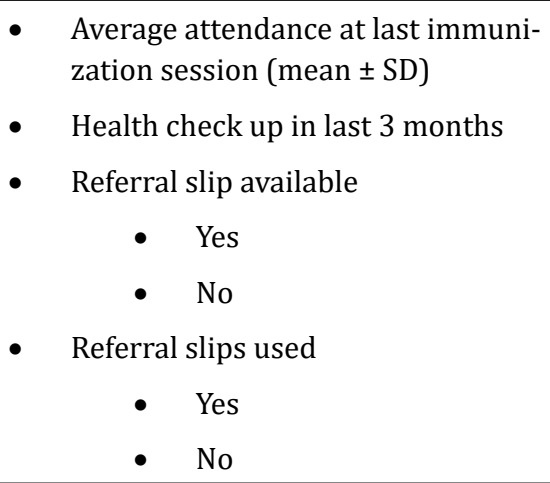 & $\begin{array}{l}89.5( \pm 9.45) \\
10(66.7) \\
9(60.0) \\
6(40.0) \\
0 \\
15(100.0)\end{array}$ \\
\hline
\end{tabular}

Table 3: Services provided at the Anganwadi centre.

\section{Discussion}

The study findings reflect a gap in the training needs of the AWWs, though all the workers had received at least one training, mostly just after their recruitment, refresher trainings were specifically lacking. An evaluation of the scheme by the National Council of Applied Economic Research (NCAER) in 60,000 AWCs during 1996 - 2001 reported that though $84 \%$ of the functionaries had received training; it was largely pre-service in nature and in-service training remained largely neglected [6]. Regular refresher training courses are extremely essential as they keep the AWWs abreast with the recent trends and changes in their field. Evolving a package of coor- dinated and joint training program for various health functionaries with provision of practical field oriented training is needed.

The AWCs visited had problems of inadequate space, lack of cooking facilities, toilets, etc., though majority of them operated from own buildings. Another study evaluating the ICDS services in Madhya Pradesh, reported apart from inadequate space, lack of cooking facilities and toilets, majority of the services were being run from rented buildings [7]. AWCs serve as centers for health education for the community and lack of basic provisions like toilet facilities results in loss of effective service delivery making people unreceptive to the health measures imparted at the center. 
Under the scheme provision should be made to provide supplementary nutrition (SN) to all the enrolled beneficiaries at every centre. Whatever the type of SN provided, it should be acceptable to all the beneficiaries. During the survey there were instances of beneficiaries not liking a particular recipe, formulating SN recipes after consultation with beneficiaries or local community leaders can be initiated. A fixed weekly menu for Hot Cooked Food was followed in all the project areas, frequent changes or alteration in the recipes will improve the response rates among the beneficiaries. The AWWs raised concern pertaining to the quality of THR being provided, as they found often that women took home the THR packets but did not prepare for themselves as they did not like the taste and rather used them as fodder for the cattle. This is a major issue and adequate quality maintenance should be done by regular monitoring of the food production and processing sites.

Growth monitoring, routine health check-ups and immunization comprise an important function of the ICDS scheme. Though the weight of the children was being recorded on a regular basis, the plotting of growth curve on the chart was inadequate. A Rajasthan based study, on evaluation of growth monitoring services, it was found that although $88.3 \%$ of AWWs received pre-placement training, and $67.5 \%$ in subsequent in-service training and with growth charts available to $83.3 \%$ of the AWWs, $75 \%$ of them were unable to use the weighing scales properly, half plotted the weights incorrectly and $57 \%$ of them were unable to interpret flattened growth curves [8]. Another assessment of the scheme stated that growth charts were maintained in only $51 \%$ of the AWCs and though all the AWWs had received the necessary training only $32.2 \%$ workers were competent to correctly plot and interpret the growth charts [9]. Fortunately, in the present study, only a few AWWs were not conversant with the plotting of growth curves.

In a review of AWCs, by NCAER in 2004 it was observed that only $64 \%$ of the centers provided health checkup for children and $53 \%$ check-up for women [10]. As also in the present study health check up for the children were conducted in only 10 centers (67\%) in the last 3 months.

There was a shortage of PSE kits and Nutrition and Health Education (NHED) kits at the AWCs, which adversely affected the PSE and NHED services. PSE activities have not been given much importance under the scheme as only 19\% of Anganwadi worker training hours have been set aside for Pre School Education activities [11]. Studies have reported poor skills development of Angan- wadi children as against the private nursery school children, which could be attributed to poor stimulating environment including lack of play materials, hence there is need to improve the preschool environment of the Anganwadis [12,13]. PSE activities need to be streamlined at the AWCs and performance appraisals of the children attending AWCs should be undertaken at regular interval to check on the quality of services provided.

In most of the AWCs there was no focus on the adolescents and their health. Supplementary nutrition in form of HCF was provided to any three of the adolescents at a time and thus there was a poor response also from the adolescents' part, often they would not turn up. Hardly any AWC provided any service to this vulnerable group through the Kishori Shakti Yojana.

\section{Conclusion}

With years of this service being run through the projects, a number of beneficiaries have been covered. However, there is a need for reappraisal and coordinated steps to optimize the functioning of the Anganwadi Centers under the scheme. Though the findings of the present study are restricted to a few AWCs, they help in providing some insight into the existing situation at the ground level. A holistic approach is needed to optimize the functioning of the scheme, identifying various issues concerning the scheme as a whole will help in reworking the policies related to women and child development. A ray of hope comes with the Ministry of Women and Child Development, announcing their ICDS reform and restructuring strategies with redefined emphasis on Early Childhood Care, Education and Development (ECCED); enhanced nutrition impact; strengthening convergence with NRHM, etc. PRI and civil society involvement; capacity development of human resources; quality improvement and public accountability and running ICDS in mission mode [14-16]. It therefore comes in significant importance that these suggested measures be realized with immediate effect so that the scheme realizes its full potential.

\section{Conflict of Interest}

The authors declare that there is no conflict of interests in the present study.

\section{Bibliography}

1. Integrated Child Development Services (ICDS) scheme. New Delhi: Ministry of women and child development, Government of India (2014). 
2. Kapil U. "Integrated Child Development Services (ICDS) scheme: a program for holistic development of children in India". Indian Journal of Pediatrics 69.7 (2002): 597-601.

3. Gupta SB., et al. "Impact of ICDS in UP". Indian Journal of Medical Research 79 (1984): 363-372.

4. ICDS-Maharashtra. Commissionerate Women and Child Development Pune (2014).

5. Dongre AR., et al. "Eliminating childhood malnutrition: Discussions with mothers and anganwadi workers". Journal of Health Studies (2008).

6. Integrated Child Development Services (ICDS) Scheme, Child Development. New Delhi: Ministry of Women and Child Development, Government of India. Evaluation of ICDS scheme (2011).

7. Dixit S., et al. "Evaluation of functioning of ICDS project areas under Indore and Ujjain division of Madhya Pradesh". The Online Journal of Health and Allied Sciences: OJHAS 9.1 (2010): 2.

8. Kapil U., et al. "Status of growth monitoring activities in selected projects of Rajasthan". Indian Pediatr 33.11 (1996): 949-952.

9. Nayar D., et al. "Assessment of community contribution to the ICDS scheme in district Agra: a case study". Indian Journal of Maternal and Child Health 10.1 (1999): 4-5.

10. Integrated Child Development Services (ICDS) Scheme, Child Development. New Delhi: Ministry of Women and Child Development, Government of India. Rapid Facility Survey of Infrastructure at Anganwadi Centers (RFS-AWCs) by NCAER (2011).

11. Nair MKC and Radhakrishnan RS. "Early Childhood Development in Deprived Urban Settlements". Indian Pediatrics 41 (2004): 227-237.

12. Thajnisa M., et al. "Growth and development status of anganwadi and private nursery school children - A comparison". Teens 1 (2007): 23-24.

13. Nair MKC and Mehta V. "Life Cycle Approach to Child Development”. Indian Pediatrics 46 (2009): S7- S11.

14. Biswas AB., et al. "Awareness and perception of mothers about functioning and different services of ICDS in two districts of West Bengal". Indian Journal of Public Health Research 54 (2010): 33-35.
15. ICDS Mission- The broad framework for implementation; Ministry of Women and Child Development Government of India (2012).

16. Report of the Inter-Ministerial Group on ICDS Restructuring. Planning Commission of India (2011).

\section{Assets from publication with us}

- Prompt Acknowledgement after receiving the article

- Thorough Double blinded peer review

- Rapid Publication

- Issue of Publication Certificate

- High visibility of your Published work

Website: www.actascientific.com/

Submit Article: www.actascientific.com/submission.php

Email us: editor@actascientific.com

Contact us: +919182824667 